\title{
An After-Effect of Pressure to the ESR Spectra of Irradiated PMMA
}

\author{
Joseph TIŇo and Ferenc Szőcs \\ Polymer Institute of the Slovak Academy of Sciences, Bratislava, Chechoslovakia.
}

(Received January 13, 1972)

\begin{abstract}
In this paper the changes in the structure of 9-line ESR spectrum of irradiated PMMA to which the pressure of $5000 \mathrm{~atm}$ has been applied are studied. The original 9-line spectrum gradually changes so that other component spectra, i.e., singlet, doublet and quartet start to prevail. These spectra correspond to polyene redicals, chain radicals of the type $-\left(\mathrm{CH}_{3}\right) \mathrm{C}\left(\mathrm{COOCH}_{3}\right)-\dot{\mathrm{C}} \mathrm{H}-\left(\mathrm{CH}_{3}\right) \mathrm{C}\left(\mathrm{COOCH}_{3}\right)-$ and allyl radicals.
\end{abstract}

KEY WORDS ESR / Irradiation / Poly(methyl methacrylate) / Radical Decay / High Pressure / Spectral Analysis /

There are many papers $^{1-6}$ which have been devoted to the interpretation of the 9-line spectrum of PMMA. This characteristic spectrum appears at room temperature when PMMA is exposed to irradiation ${ }^{1}$, mechanical destruction ${ }^{7}$ or to the effect of initiators at high pressure ${ }^{8}$. The earlier assumption that it is a spectrum resulting from and consisting of several component spectra (several radicals) ${ }^{2,3,7}$ or that it is the spectrum of the same radical in different conformations $^{1}$ has been replaced by the model now generally accepted. In this the spectrum is thought to be due to a single radical (end radical), but of the 16 original lines only 9 are observable. $^{4}$

The spectrum, which is observed at low temperatures by using irradiated samples is modified by the presence of other kinds of radical. ${ }^{9}$ However, some changes in the structure of the spectrum appear at higher temperatures and the samples have therefore been themostatted at temferature above room temperature. ${ }^{10,11}$ The intensity ratio of lines changes in this case and in particular, the intensity of lines 4 and 6 increases with respect to the other lines of the spectrum. This study aims at a thorough investigation of changes in the structure of 9-line spectrum. To achieve this, it is best to work at the extreme conditions which ensue from the application of high pressure to the samples under investigation.

\section{EXPERIMENTAL}

The measurements were carried out with PMMA samples (Commercial name Plexiglas 233, $\left.M_{W}=3 \times 10^{6}\right)$ of the firm Rhôm and Hans, limited. Polyglycol-metacrylate samples were polymerized in the presence of $1 \%$ of dibenzoylperoxide in test tubes of Woods metal at $50^{\circ} \mathrm{C}$ for 6 hours. The samples with varying degree of cross-linking were obtained by polymerizing monoethyleneglycol methacrylate with differing contents of monoethylenebisglycol methacrylate $(0.16-50 \%$ by weight).

Free radicals were generated by irradiating the samples with a dose of approximately 4 Mrad. The ESR spectra were measured after irradiating and then again as follows. The cooled samples were transferred into the pressure matrix, exposed to a pressure of $5000 \mathrm{~atm}$ and heated quickly to the required temperature. After $30 \mathrm{~min}$ thermostating in insert atmosphere under pressure, they were quickly cooled and, on pressure release, transferred, they were quickly cooled and, on pressuse release, transferred in the cooled state into the cavity resonator of the ESR spectrometer. This method has been described in more detail elsewhere. ${ }^{12}$ The measurements were performed by means of the X-band ESR apparatus with an AEG spectrometer. 


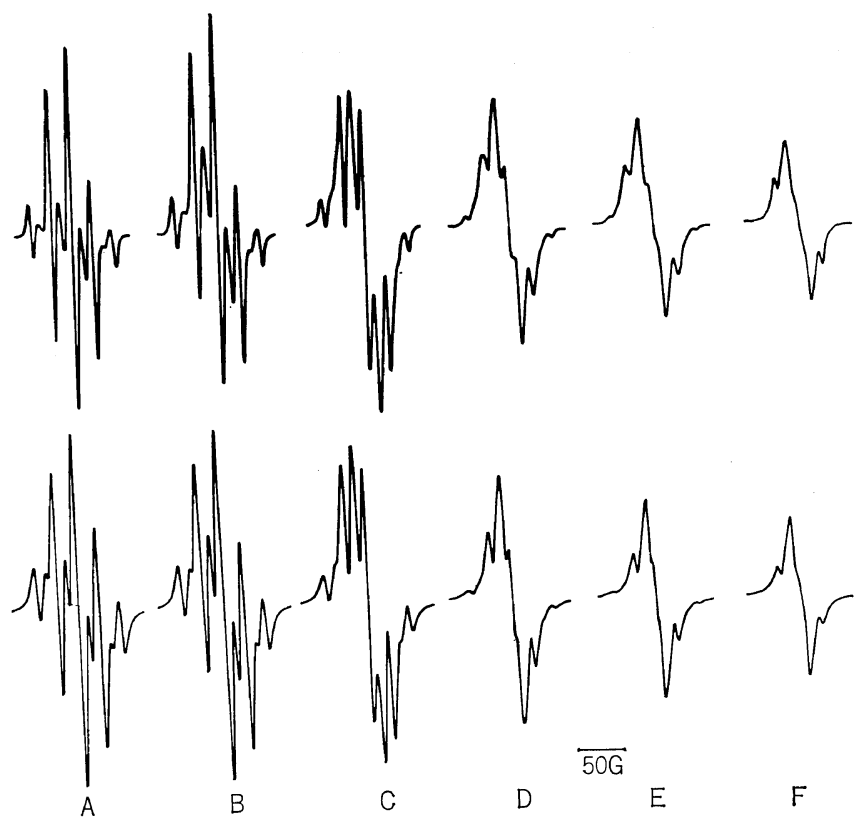

Figure 1. Experimental (at the top) and theoretical (at the bottom) ESR spectra of irradiated PMMA after $30 \mathrm{~min}$ thermostating at different temperatures and 5000 atm: $\mathrm{A}$, room temperature and atmospheric pressure; $\mathrm{B}, 110^{\circ} \mathrm{C} ; \mathrm{C}, 120^{\circ} \mathrm{C} ; \mathrm{D}, 130^{\circ} \mathrm{C} ; \mathrm{E}, 140^{\circ} \mathrm{C}$; $\mathrm{F}, 155^{\circ} \mathrm{C}$.

\section{RESULTS AND DISCUSSION}

The ESR spectrum which has been obtained with irradiated PMMA at room temperature has a characteristic shape and consists of 9-lines (Figure 1). The shape of this spectrum changes with temperature but this change is not significant. ${ }^{10}$ Many changes due to temperature follow from the model proposed by Fischer. ${ }^{4,17}$ Somewhat larger changes in the structure of ESR spectrum due to altered conditions led to the conclusion that, in the irradiated PMMA, besides the end radicals the presence of chain

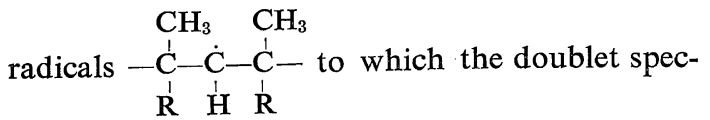

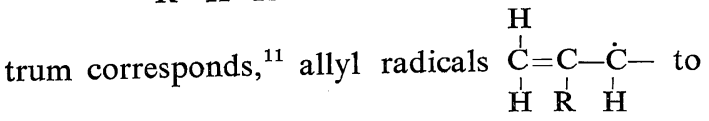
which the quartet spectrum corresponds ${ }^{13}$ and polyene radicals to which singlet spectrum corresponds $^{15}$ must be assumed. The application of high pressure to the polymer sample shifts the interval of free radical decay to considerably higher temperatures ${ }^{12}$. In this temperature region the relative stability of radicals should in general be different. It may, therefore, be expected that other component spectra start to prevail in the overall spectrum. Figure 1 (at the top) presents the ESR spectra (Figure $1 \mathrm{~B}$ F) of irradiated PMMA exposed to a pressure of $5000 \mathrm{~atm}$. Even the spectrum B differs considerably from the well known 9-line spectrum (Figure 1A) and the change increases with temperature. The last spectrum (Figure $1 \mathrm{~F}$ ), due to heating the sample under pressure to $155^{\circ} \mathrm{C}$, does not contain any more traces of end radical. As is evident from the figure, the overall spectrum consists of a few component spectra. Radicals belonging to these spectra are present in larger or smaller amounts at every temperature. The individual concentration of each radical may be determined to the best advantage by an exact statement of the overall structure of the spectrum. For this purpose the method of Hauvel and Lind ${ }^{14}$ is suitable. This method in modified form has been used for the construction of theoretical spectra by using the following spectra (Table I). 
Table I.

\begin{tabular}{lcc}
\hline & $\begin{array}{c}\text { Half of line } \\
\text { width, G }\end{array}$ & $a_{\mathrm{H}}, \mathrm{G}$ \\
\hline 9-Line srectrum $^{4}$ & 6 & $\begin{array}{c}\text { Accoding to } \\
\text { Fisher }\end{array}$ \\
& & \\
Doublet spectrum $^{11}$ & 6 & 22.56 \\
Quartet spectrum $^{13}$ & 6 & 14.5 \\
Singlet spectrum $^{15}$ & about $10^{\mathrm{a}}$ & - \\
\hline
\end{tabular}

a The line width variation $( \pm 2 G)$ width temperature had to be assumed in this spectrum.

The theoretical spectra thus constructed are at bottom in Figure 1B. The radicals corresponding to the component spectra used were observed in the ESR study of the PMMA irradiated under different conditions. ${ }^{4,11,13}$ Since the theoretical spectra are in good agreement with the experimental one and it is sufficient to alter the relative proportions of component spectra in the overall spectrum in order to obtain a correct description of the change in the structure of spectrum, it is concluded that the model used is correct. The part played by individual spectra in the composite spectra given in Figure 1, is evident from Figure 2 which shows the dependence on temperature of free radical concentration in arbitrary units. The end radical decays rapidly with increasing tem-

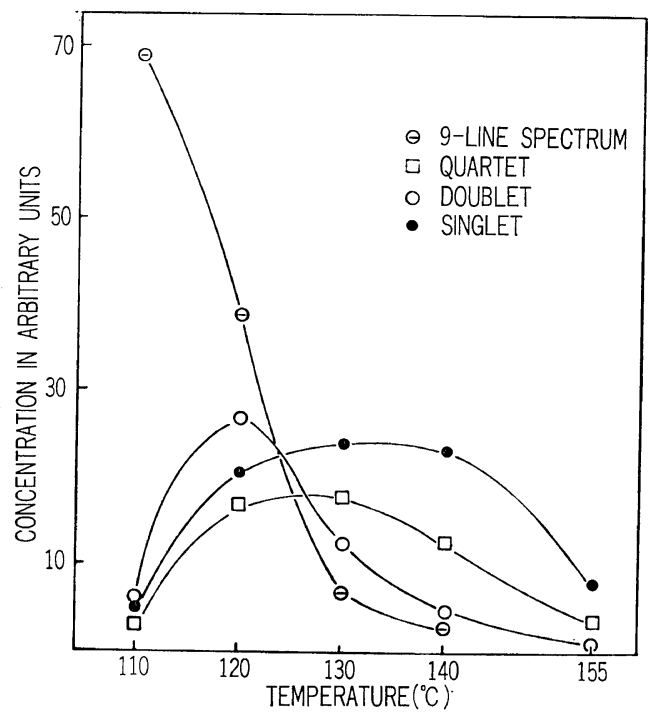

Figure 2. Dependence of free radical concentration on temperature after $30 \mathrm{~min}$ thermostating at $5000 \mathrm{~atm}$. perature. At the same time other three radicals appear and their concentration rises up to a temperature of $120^{\circ} \mathrm{C}$. At this temperature, the intensity of the doublet spectrum begins to decrease. At higher temperatures, the structure of the spectrum is determined in principle by two radicals namely polyene and allyl. The most stable radical in this system is polyene (Figure 2).

It is known that allyl radicals are more stable in polymers than alkyl radicals and that they start to preponderate at the temperatures above $-30^{\circ} \mathrm{C} .^{16}$ From this point of view the increased contribution of allyl and polyene radicals in the overall spectrum appears reasonable. Radicals within the chain (double spectrum) are also relatively stable. Its stability may be interpreted by a steric hindrance as well as on the basis that the mobility of segments (which is important for the reactivity of this radical) decreases due to the effect of pressure. ${ }^{11}$ On the other hand, the pressure has practically no direct influence on the mobility of chain ends and that is why it stabilizes the end radicals to a lesser extent.

In the case of the spectrum of cross-linked polyglycol metacrylate, an effect similar to that of pressure may be observed. Cross-linking also reduces the mobilizy of segments and should

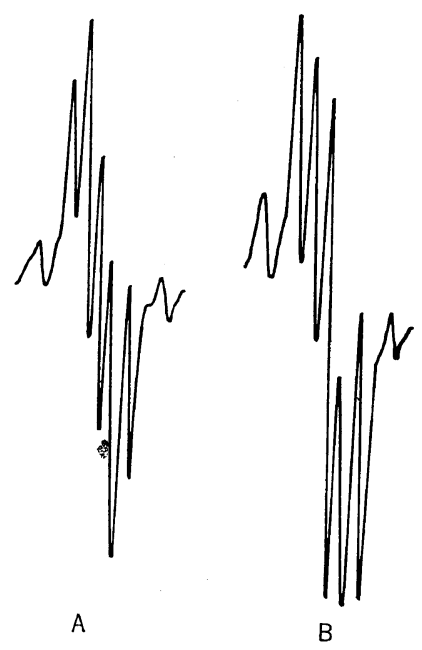

Figure 3. ESR spectra of cross-linked polyglycol metacrylate at room temperature: A, 20-\% crosslinking; B, 30\% cross-linking. 
bring about changes in the spectrum which are similar to those effected by pressure. Figure 3 presents ESR spectra of two differently crosslinked polymers. This effect is however, not, so marked as in the case of pressure treatment and may be due to the fact that the decay takes place at lower temperatures (below $70^{\circ} \mathrm{C}$ ) where the concentration of end radical is still relatively high.

\section{REFERENCES}

1. M.C.R. Symons, J. Amer. Chem. Soc., 2, 1186 (1963).

2. A.T. Bullock and L.H. Sutcliffe, Trans. Faraday Soc., 60, 625 (1964).

3. J.S. Milevskaja and M.V. Volkenstejn, Optika Spektroskopiya, 11, 349 (1961).

4. H. Fischer, J. Polym. Sci. Part B, 2, 529 (1964).

5. P. Kouř́m and K. Vacek, Trans. Faraday Soc., 61, 415 (1965).
6. J. Sohma, J. Polym. Sci. Part B, 3, 287 (1965).

7. S.E. Bresler, E.N. Kazbekov, and E.M. Saminskij, Vysokomol. Soedin., 1, 132, 1374 (1959).

8. F. Szócs, J. Plaček, and È. Borsig, J. Polym. Sci. Part B, 9, 753 (1971).

9. Y. Hajimoto, N. Tamura, and S. Okamoto, $J$. Polym. Sci. Part A, 3, 255 (1965).

10. I.D. Campbell and F.D. Looney, Australian J. Chem., 15, 642 (1962).

11. F. Szöcs and K. Ulbert, J. Polym. Sci. Part B, 5, 671 (1967).

12. F. Szöcs, J. Appl. Polym. Sci., 14, 2629 (1970).

13. A.T. Bullock, G.G. Cameron, and B.D. Nicol, Chem. Zvesti, 26, 193 (1972).

14. H.M. Heuvel and K.C.J.B. Lind, J. Polym. Sci., Part A-2, 8, 401 (1970).

15. S. Ohnishi, Y. Ikeda, M. Kashiwagi, and I. Nitta, Polymer, 2, 119 (1961).

16. D.C. Waterman and M. Dole, J. Phys. Chem., 74, 1913 (1970).

17. M. Iwasaki and Y. Sakai, J. Polym. Sci., Part A-1, 7, 1537 (1969). 